\title{
İstanbul İçin Standart Süreli Gözlenen En Büyük Yağışların Eğilimleri
}

\author{
Kevser ŞEN ${ }^{1}$ \\ Hakan AKSU ${ }^{2}$
}

\section{ÖZ}

İklim değişkenliği ve değişimi, hidrolojik çevrimin her bir parametresini etkilemektedir. Yağışların şiddet, süre ve tekerrürleri köprüler, menfezler, şehir yağmursuyu drenajlarının tasarımında kullanılan temel bilgidir. $\mathrm{Bu}$ çalışmada İstanbul ve civarındaki 7 adet plüviograflı MGİde ölçülen standart süreli maksimum yağışların eğilim analizleri yapılmıştır. Veri serileri, iki eşit döneme bölünerek yağış şiddet tekerrür eğrileri oluşturulmuştur. Kartal MGİ haricinde 6 istasyonda (Sarıyer, Kumköy, Florya, Çorlu, Göztepe ve Şile) belirgin artış eğilimleri belirlenmiştir. Bir örnek olarak, Sarıyer meteoroloji istasyonunun 5 saatlik standart süreli 2 yıl tekerrürlü maksimum yağgşları ilk dönem ve ikinci dönem hesaplanan bağıl farkları \%30 ve Sarıyer'de bulunan Bekar deresinde Q Q00 taşkın debisindeki $\% 60$ artış şeklindedir.

Anahtar Kelimeler: Eğilim, yağış şiddet-süre-tekerrür eğrisi, maksimum yağışlar, iklim değişkenliği ve değişimi, İstanbul.

\section{ABSTRACT}

\section{Trend Analysis of Observed Standard Duration Maximum Precipitation for Istanbul}

Climate variability and change effects each parameter of hydrological cycle. Intensity, duration and frequency of precipitation is the basic information used in the design of bridges, culverts, city storm drainages. In this study, trend analysis of standart duration maximum precipitation was performed for 7 meteorological station equipped with pluviograph and located in İstanbul and around. Data series were divided two equal periods and precipitaion intensity-duration and frequency curves were developed. Except for Kartal MGI, significant increase trend were detected in 6 stations (Sarıyer, Kumköy, Florya, Çorlu, Göztepe ve Şile). As an example, relative difference between first and second half is $30 \% 5$ hour standart

\footnotetext{
Not: Bu yazı

- Yayın Kurulu'na 16 Kasım 2019 günü ulaşmıştır. 17 Nisan 2020 günü yayımlanmak üzere kabul edilmiştir.

- 31 Mart 2021 gününe kadar tartışmaya açıktır.

- https://doi.org/10.18400/tekderg.647558

1 DSİ 14. Bölge Müdürlügüü, İstanbul - kevsers@dsi.gov.tr https://orcid.org/0000-0002-7323-0312

2 Samsun Üniversitesi, Meteoroloji Mühendisliği Bölümü, Samsun - hakan.aksu@samsun.edu.tr https://orcid.org/0000-0003-4686-7446
} 
duration and 2 years frequecy maximum precipitation for Sarıer MGI and Q 500 design flood discarge increased 60\% Bekar Creek in Sarıyer.

Keywords: Trend, intensity-duration-frequency curves, Maximum rainfalls, climate variability and change, İstanbul.

\section{GİRIŞ}

İklim değişkenliği ve değişiminin en önemli sonucu, yere yakın atmosferik sıcaklıklarda son otuz yılda gözlenen belirgin artışlardır. Artan hava sıcaklıklarının atmosferin su tutma kapasitesini her $1{ }^{\circ} \mathrm{C}$ sıcaklık artışına karşılık olarak \% 7 oranında artırması ve bu durumun ise yağış miktarını etkilemesi beklenir [1]. Bunun sonucu olarak ortalama yağışlar ve akımlar iklim değişikliği ile dünyanın farklı yerlerinde azalma ve artma eğilimleri göstermektedir. Ayrıca sıcaklık artışları ile birlikte ekstrem yağışlarda da bir artış eğilimi beklenmektedir [2, $3,4,5]$.

Yağış Şiddet-Süre-Tekerrür eğrileri (YŞST) yağmursuyu drenajı, köprü, menfez, dolusavak vb. su yapılarının tasarım debilerinin tahmini için gerekli ekstrem yağış değerlerinin belirlenmesinde kullanılmaktadır. YŞST gözlenen standart süreli yıllık yağış maksimum veri serisi veya belirli bir değerin üzerindeki maksimum değerlerin veri serisinin teorik bir dağılım fonksiyonuna benzeştirilmesi esasına göre çizilir [6]. YŞST eğrilerinin kullanımı 1930'lu yılların başlarına kadar uzanır [7]. Daha sonra YŞST eğrilerinin değişik dağılım fonksiyonları ile oluşturulması ve risk analizlerinde kullanılması konusunda pek çok çalışma gerçekleştirilmiştir $[8,9,10,11,12,13]$. Halihazırda kullanılan eğriler, ekstrem yağışların gerçekleşme olasılıklarının zaman içerisinde değişmediği kabulüne (durağanlık) dayanmaktadır. Oysa yukarıda bahsedildiği şekilde, ekstrem yağışların süre, şiddet ve frekanslarında değişim öngörülmektedir.

Dünyada standart süreli maksimum yağış veri serilerinde eğilim analizleri konusunda çalışmalardan örnekler Kanada [14], Japonya [15], ABD [5], ABD’nin kuzeydoğusu [16] olarak verilebilir. Bu çalışmalarda genelde Mann-Kendall parametrik olmayan eğilim analizi ve doğrusal regresyon testi, ile gerçekleştirilmiş, sonuç olarak artış eğilimleri tespit edilmiştir. Bununla birlikte yine ABD'nin orta-batı bölgesinde gerçekleştirilen bir çalışmada eğilim tespit edilmemiştir [17]. Güneydoğu Asya ve Güney Pasifik’te yapılan bir çalışmada ekstrem yağışların miktarında artış, frekansında ise azalma eğilimi tespit edilmiştir [18]. Westra ve arkadaşları[19] yıllık maksimum yağışlar için global ölçekte gerçekleştirdiği çalışmada istasyonların büyük çoğunluğunda artış eğilimi tespit etmiştir.

Türkiye'de ise maksimum yağışların eğilim analizleri konusunda çalışmalar sınırlı sayıdadır. Haktanır ve Çıtakoğlu [20] Türkiye genelinde uygulama yaptıkları 174 istasyonun \%90 ında eğilim olmadığı sonucuna varmışlardır. Bununla birlikte Marmara Bölgesinde incelenen 24 istasyonun \%17 sinde hem doğrusal regresyonla, hem de Mann-Kendall sonuçlarına göre eğilim tespit edilmiştir. Karahan ve arkadaşları [21], GAP bölgesi içinde yer alan Adıyaman, Diyarbakır, Gaziantep ve Şanlıurfa meteoroloji istasyonlarına ait yağış verilerini kullanarak bu illere ait şiddet-süre-frekans bağıntısını genetik algoritma optimizasyon tekniği ile elde etmişlerdir. Şiddet-süre-frekans ilişkisinin belirlenmesinde alternatif bir teknik olarak önerilen çözüm algoritmasının; uygulandığı GAP illeri için çok iyi sonuç verdiği gösterilmiştir. Çözüm bölgesinin tümünün pratik uygulamalarda kullanılmak üzere tek bir 
denklemle ifade edilmesinin mümkün olabileceğini ortaya koymuşlar, önerilen denklem yardımıyla yağış ölçümü bulunmayan yerleşim yerleri için de şiddet-süre-frekans ilişkisi belirlenebileceğini öngörmüşlerdir. Almazroui ve arkadaşları [22] Türkiye'nin güneyinde ve Suudi Arabistan'da gerçekleştirdikleri çalışmada yıllık maksimum yağış veri serilerinde ilk dönem ve ikinci dönem olarak ayırdıkları veri serileri arasında sırasıyla $\% 5$ ve $\% 15$ iklim değişimi etkisiyle artış tespit etmişlerdir. Almazroui ve arkadaşları [22] yaptıkları bu çalışma sonucunda, Türkiye'nin yarı kurak bölgelerinde geleceğe yönelik projelerde yağış şiddetinin $\% 5$ artırılarak kullanılmasını önermişlerdir. Korkmaz ve arkadaşları [23] Orta Karadeniz Bölgesinde 8 Meteoroloji Gözlem istasyonunda YŞST eğrilerindeki dönemsel değişimleri incelemişler, iki dönem ve tüm periyot için 2 istasyonda belirgin artış trendi tespit etmişlerdir. Güçlü ve arkadaşları [24] Florya istasyonunda yağış şiddetlerinde ise azalma eğilimi tespit etmişlerdir.

$\mathrm{Bu}$ çalışmada, İstanbul ili ve civarında bulunan plüviyograf kaydına sahip ve uzun süreli gözlemleri bulunan istasyonlar için yağış-şiddet-süre ve tekerrür eğrilerindeki eğilim detaylı olarak incelenmiştir. Çalışma yöntemi ilk olarak veri serilerinin eğilim analizleri için elverişli olup olmadıklarının belirlenmesi (Homojenlik, iç bağımlılık testleri) ve daha sonra yaygın kullanılan eğilim analizleri (Mann-Kendall, Sen'in Eğim testi) ile birlikte yenilikçi eğilim metodu ile ilk dönem ve son dönem arasındaki değişimin incelenmesidir. Dağılım uygunluk testleri ile yıllık maksimum yağışlara en uygun olasılık dağılımı belirlenerek, 14 standart süre için YŞST eğrileri veri serisinin birinci ve ikinci dönemleri için ayrı ayrı elde edilmiş, İstanbul şehri için yağış şiddetlerinde görülen değişim belirlenmiştir. Sarıyer MGİ istasyonu tarafından temsil edilen 7,0 km² yağış alanına sahip Bekar Deresinde, şehirleşme etkisi dikkate alınmadan, sadece iklim değişkenliği ve değişiminden kaynaklanan taşkın debisinde oluşan fark hesaplanmıştır.

\section{HİDROMETEOROLOJİK VERİ VE ÇALIŞMA ALANI}

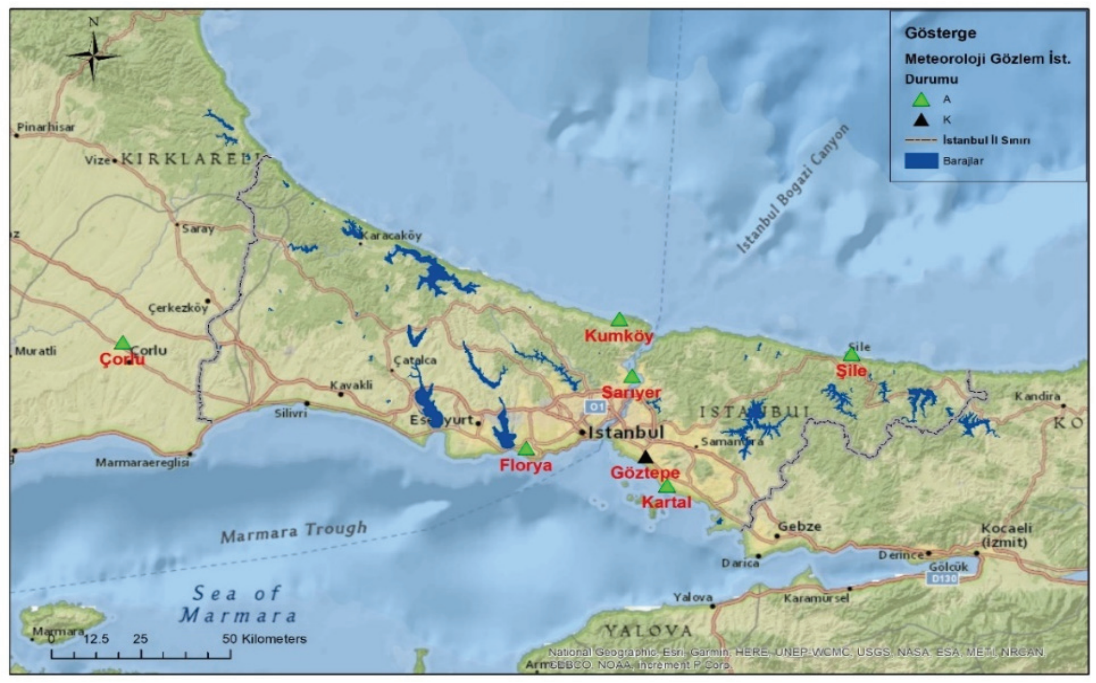

Şekil 1 - Çalışma Alanı 
Çalışmada kullanılan veriler, Meteoroloji Genel Müdürlüğü (MGM) tarafından işletilmekte olan Florya, Sarıyer, Kumköy, Çorlu, Şile, Göztepe, ve Kartal olmak üzere İstanbul ili ve civarındaki plüviyograflı yedi adet meteoroloji gözlem istasyonuna (MGI) ait standart süreli ( $5 \mathrm{dk}, 10 \mathrm{dk} ., 15 \mathrm{dk}, 30 \mathrm{dk}, 1 \mathrm{sa}, 2 \mathrm{sa}, 3 \mathrm{sa}, 4 \mathrm{sa}, 5 \mathrm{sa}, 6 \mathrm{sa}, 8 \mathrm{sa}, 12 \mathrm{sa}, 18 \mathrm{sa}, 24 \mathrm{sa}$ ) yıllık en büyük yağış yüksekliği (mm) değerleridir. Çalışma alanı Şekil-1'de verilmişstir.

Araştırılan yerlerdeki plüviyograflı yağış istasyonlarının kuruluş tarihlerinin farklı olması sebebiyle veri sayılarında çeşitlilikler mevcuttur. Her istasyonda ölçümün yapılmaya başlandığı yıldan, 2010 ve 2015 yılına kadar ölçülen tüm veriler kullanılmıştır (Tablo 1).

\section{Çizelge 1 - Meteoroloji Gözlem Ístasyonları Karakteristikleri}

\begin{tabular}{|l|c|c|c|c|}
\hline \multicolumn{1}{|c|}{ İstasyonun Adı } & Kotu (m) & Enlem/Boylam & $\begin{array}{c}\text { Issleten } \\
\text { Kuruluş }\end{array}$ & Gözlem Periyodu \\
\hline Florya & 36 & $40^{\circ} 59^{\prime} \mathrm{K}-28^{\circ} 48^{\prime} \mathrm{D}$ & MGM & $1938-2015$ \\
\hline Sarıer & 58 & $41^{\circ} 08^{\prime} \mathrm{K}-29^{\circ} 04^{\prime} \mathrm{D}$ & $\mathrm{MGM}$ & $1955-2015$ \\
\hline Çorlu & 183 & $41^{\circ} 10^{\prime} \mathrm{K}-27^{\circ} 47^{\prime} \mathrm{D}$ & $\mathrm{MGM}$ & $1938-2015$ \\
\hline Şile & 83 & $41^{\circ} 11^{\prime} \mathrm{K}-29^{\circ} 37^{\prime} \mathrm{D}$ & $\mathrm{MGM}$ & $1938-2015$ \\
\hline Kartal & 27 & $40^{\circ} 54^{\prime} \mathrm{K}-29^{\circ} 06^{\prime} \mathrm{D}$ & $\mathrm{MGM}$ & $1950-2010$ \\
\hline Kumköy & 30 & $41^{\circ} 15^{\prime} \mathrm{K}-29^{\circ} 02^{\prime} \mathrm{D}$ & $\mathrm{MGM}$ & $1951-2015$ \\
\hline Göztepe & 33 & $40^{\circ} 58^{\prime} \mathrm{K}-29^{\circ} 05^{\prime} \mathrm{D}$ & $\mathrm{MGM}$ & $1929-2007$ \\
\hline
\end{tabular}

\section{YÖNTEM}

Hidro-meteorolojik değişkenler için eğilimin belirlenmesinde Mann-Kendall test ve Sen'in eğim tahmini yöntemi çok yaygın olarak kullanılmakta ve çok iyi bir performans ortaya koymaktadır. Hidro-meteorolojik parametrelere ilişkin yapılacak olan eğilim analizi, su kaynaklarının daha iyi yönetimi ve planlanmasında yöneticilere birçok fayda sağlar [25].

Bu çalışmada İstanbul ili ve civarında bulunan Meteoroloji Gözlem İstasyonlarının (MGİ) standart süreli yıllık maksimum yağış değerlerinin homojenliği ve iç bağımlılığ 1 incelenmiş, zaman serilerinin içerisinde eğilim bileşeni barındırıp barındırmadıkları ise Mann-Kendall non-parametrik testi, Sen'in eğilim testi ve ayrıca Yenilikçi Şen Yöntemi ile analiz edilmiş, eğilim bileşeni barındıran veri serileri için yağış şiddet süre eğrileri, iki farklı dönem ve tüm periyod için olmak üzere hesaplanmıştır. İlk dönem ve son dönem yağış şiddetlerindeki değişim incelenmiştir. Ayrıca belirgin anlamlı artış eğilimi gösteren bir istasyonda maksimum yağışların şiddetinde görülen artışın, maksimum taşkın debisine olan etkisi belirlenmiştir.

\subsection{Run (Swed-Eisenhart) Homojenlik Testi}

Zaman serilerinde verilerin aynı toplumdan gelip gelmediklerini belirlemek için yaygın olarak kullanılan bir testtir. Run testi ile veri serisinin aynı toplumdan geldiği veya gelmediği ve birbirinden bağımsız olduğu veya bağımsız olmadığ 
Verilerin homojenliği için yapılan varsayımlar şunlardır; H0: Veriler Homojendir. H1: Veriler Homojen değildir. Test sonucu z, veri sayısı $N$, run (değişim) sayısı $\mathrm{r}$, orta seviye altında olanlar sayısı $\mathrm{Na}$, üstte olan değerler sayısı $\mathrm{Nu}$ olmak üzere;

$Z=\frac{r-\frac{2 N a N u}{N a+N u}+1}{\sqrt{\frac{2 N a N u(2 N a N u-N)}{N^{2}-(N-1)}}}$

Elde edilen $z=$ değeri \pm 1.96 arasında ise $\% 95$ güven aralığında, \pm 2.54 aralığında ise $\% 90$ güven aralığında verilerin rastgele (homojen) dağıldığ 1 kabul edilir.

\subsection{Otokorelasyon (İç Bağımlılık) Sayısının Önemlilik Testi}

İç bağımlılık barındıran veri serlerinde parametrik olmayan eğilim analizleri uygulanmadan önce iç bağımlılığın giderilmesi gerekmektedir. Bu nedenle standart süreli maksimum yağış veri serilerinde öncelikle İç Bağımlılık Sayısının Önemi testi ile iç bağımlılık analizi yapılmış, sonrasında ise i. Bağımlılık tespit edilen veri serilerine iç bağımlılığı gidermek için ön beyazlatma (prewhitening) işlemi uygulanmıştır.

Bir veri serisinde, ardışık gözlemler arasındaki bir gecikmeli otokorelasyon katsayısının büyüklüğü, ardışık gözlemler arasındaki bağımlılığın ölçüsünü verir. Rastgele karakterli bir serinin popülasyon otokorelasyon fonksiyonu, lag $\neq 0$ için, sıfır veya sıfıra önemli ölçüde yakındır. Bir gecikmeli otokorelasyon katsayısı, denklem (2) ile belirlenir [27].

$r_{1}=\frac{\sum_{i=1}^{n-1}\left(x_{i}-\bar{x}\right)\left(x_{i+1}-\bar{x}\right)}{\sum_{i=1}^{n}\left(x_{i}-\bar{x}\right)^{2}}$

Burada: $x_{i}$ ve $x_{i}+1$ sırasıyla $i$ ve $i+1$. Gözlem değerini, $x$ gözlem serisinin ortalamasını, $n$ serideki gözlem sayısını göstermektedir. H0:r1=0 hipotezi, H1:rl $\neq 0$ alternatif hipotezine karşılık test edilir. Hesaplanan r1 değeri, \%5 önem düzeyinde, denklem (6) ile hesaplanan alt ve üst güven sınırları arasında kaldığı takdirde, \%95 güvenle ardışık gözlemler arasında korelasyonun önemsiz olduğuna karar verilir.

$C L\left(r_{1}\right)=\frac{-1 \pm 1.96 \sqrt{n-2}}{n-1}$

Burada: n, serideki toplam gözlem sayısını göstermektedir.

\section{Ön Beyazlatma İşlemi (Prewhitening)}

Veri serisinde bir gecikmeli iç bağımlılık tespit edilmesi halinde veri serisinin bağımsız hale getirilmesinde Von Storch ve Navarra [28] tarafından önerilen ön beyazlatma işlemi yaygın olarak kullanılmaktadır. $x^{\prime}$ ön beyazlatma sonucu, $x_{i}$ original veri ve $n$ ise veri sayısını ifade etmektedir. Hesaplama adımlar denklem 4, 5 ve 6 da sunulmuştur.

$x_{i}=x_{i}-\rho x_{i-1}$ 
$\rho=\frac{\frac{1}{n-1} \sum_{i=1}^{n-1}\left(x_{1}-E\left(x_{\mathrm{i}}\right)\right)\left(x_{\mathrm{i}+1}-E\left(x_{\mathrm{i}}\right)\right)}{\frac{1}{N} \sum_{\mathrm{i}=1}^{n}\left(x_{i}-\left(x_{i}\right)\right)^{2}}$

$\left(x_{i}\right)=\frac{1}{n} \sum_{i=1}^{n} x_{i}$

\subsection{Mann-Kendall Testi}

Hidrometeorolojik zaman serilerinin eğilim belirlenmesinde yaygın olarak kullanılan parametrik olmayan bir metottur [29,30]. Mann-Kendall testinin istatistiği $S$ aşağıdaki (7) ifadesiyle hesaplanır. Bu eşitlikteki $\left(x_{j}-x_{k}\right)$ değerinin işareti ise (8) ifadesinden bulunur.

$S=\sum_{k=1}^{n-1} \sum_{j=k+1}^{n} \operatorname{sgn}=\left(x_{j}-x_{k}\right)$

$\operatorname{sgn}\left(x_{j}-x_{k}\right)=\left\{\begin{array}{cc}+1 \text { Ĕger } & \left(x_{j}-x_{k}\right)>0 \\ 0 \text { Ĕg er } & \left(x_{j}-x_{k}\right)=0 \\ -1 \text { Ĕger } & \left(x_{j}-x_{k}\right)<0\end{array}\right\}$

Asimptotik olarak, normal bir dağılıma sahip ve ortalaması sıfır olan test istatistiği $S^{\prime}$ 'in varyans1

$\operatorname{Var}(S)=\frac{n(n-1)(2 n+5)}{18}$

Eğer zaman serisinde benzer değerler varsa varyans hesabı;

$\operatorname{Var}(S)=\frac{n(n-1)(2 n+5)-\sum t(t-1)(2 t-5)}{18}$

şeklinde hesaplanır. Varyansı belirlenen Mann-Kendall testinin anlamlı bir eğilim tespit edip etmediği standart normal değişken z'nin aşağıdaki eşitlikle hesaplanıp kritik z değeriyle karşılaştırılmasıyla belirlenir.

$Z=\left\{\begin{array}{l}\frac{s-1}{\sqrt{\operatorname{Var}(S)}} \text { Ĕg } \operatorname{er} S>0 \\ 0 \quad \text { Ĕger } \quad S=0 \\ \frac{S+1}{\sqrt{\operatorname{Var}(S)}} \text { Ĕg er } S<0\end{array}\right\}$

Eğer seçilen $\alpha$ anlamlılık seviyesinde $|z| \leq z_{\alpha}$ ise H0 hipotezi kabul edilir, değilse reddedilir. Hesaplanan $S$ değeri pozitif ise artan, negatif ise azalan bir trendin varlığı söz konusudur. Yöntemin en önemli avantajı dağılımdan bağımsız olması ve eksik verilerle çalışmaya imkân vermesidir. 


\subsection{Sen Eğilim Tahmin Metodu}

Zaman serilerinde doğrusal bir eğilim olması durumunda, eğim parametrik olmayan bir metot kullanılarak belirlenebilir. $\mathrm{Bu}$ metot veri hatalarından veya ekstrem değerlerden etkilenmeyen ve eksik değerlerin bulunduğu kayitlara uygulanabilmektedir [31]. $j$ ve $k$ zamanlarındaki veriler $x_{j}$ ve $x_{k}$ olmak üzere $(j>k$ şartı ile); $N=n(n-1) / 2$ ( $n$ zaman periyotlarının sayısı) adet $Q_{i}(i=1,2,, \ldots, N)$ değeri denklem (12) ifadeye göre hesaplanır.

$Q_{i}=\frac{\left(x_{j}-x_{k}\right)}{(j-k)}$

Hesaplanan $Q_{i}$ değerleri küçükten büyüğe doğru sıralanır. Bu $N$ adet $Q_{i}$ değerlerinin medyanı Sen'in Eğim Tahmincisi olarak kullanılır. $\mathrm{N}$ adet $Q_{i}$ değerinin medyanı alınarak ilgili gözlemin birim zamandaki değişimi $N$ sayısı tek ise denklem (13), çift ise denklem (14) ile belirlenir.

$Q=Q_{(N+1) / 2}$

$Q=\left\{\frac{1}{2}\left[Q_{N / 2}+Q_{(N+2) / 2}\right]\right\}$

\subsection{Yenilikçi Şen Yöntemi}

$\mathrm{Bu}$ yöntemin temelinde, eğer iki zaman serisi birbiriyle özdeş ise serilerden birinin diğerine karşı noktalanması sonucu noktaların Kartezyen koordinat sisteminde 1:1 (45) eğrisi üzerinde saçılacağı gerçeği yatmaktadır. Bu tür bir yaklaşım kayıtlı verilerin geçmiş davranışları hakkında bilgi vermektedir. Şekil 2'den görüldüğü üzere, verinin 1:1 doğrusunun üzerinde sıralanması eğilimin olmadığını göstermektedir. Şayet veriler 1:1 doğrusunun altında kalan üçgende kalıyorsa azalan bir eğilim; üstte kalan üçgende yer alıyorsa artan bir eğilim olduğu sonucuna varılır. Verinin 1:1 doğrusuna yaklaşması trendin büyüklüğünün (eğim) zayıflaması demektir [32].

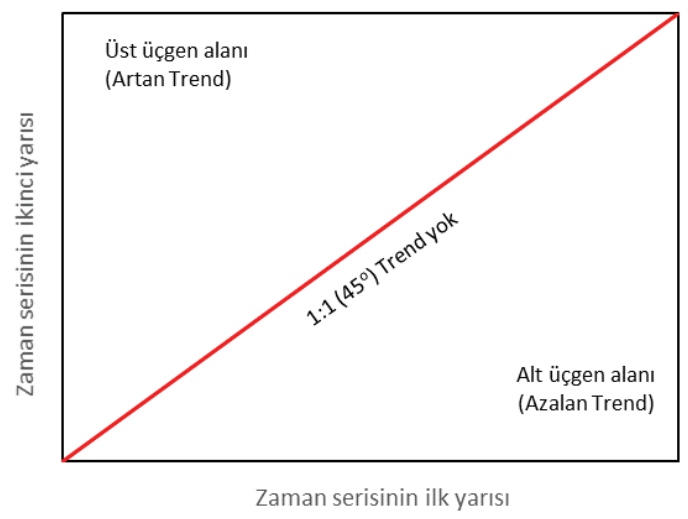

Şekil 2 - Yenilikçi Şen Yöntemi 
Tüm veri aralıklarında yorumlanabilmesi Şen'in yönteminin yenilikçi özelliği olup metot, Şen tarafından Tuna Nehri yıllık akımlarına, Aslantas Barajı, Menzelet Barajı ve Fırat Nehri üzerinde kurulu Cizre akım gözlem istasyonu verilerine uygulanmıştır [33]. Yöntem, iklim değişikliğinin Batı Karadeniz Havzasının yağış verilerine etkisini ortaya koymak adına 10 adet istasyonda uygulanmış, 4 istasyonda azalan eğilimler görülürken 5 istasyonda eğilim görülmemiştir. 1 istasyonda ise artan trende rastlanmıştır [34].

Yenilikçi Şen Yöntemi, zaman serisinin muhtemel eğilim bileşenleri hakkında görsel bir inceleme imkânı sunduğu için avantajlı bir yöntemdir. Artan (azalan) eğilim hakkında bilgi veren eğim $S ; \quad \bar{R}_{1}$ ve $\bar{R}_{2}$ sirasıyla zaman serisinin ilk yarısı ve ikinci yarısının aritmetik ortalaması ve $n$ gözlem sayısı olmak üzere, aşağıdaki denklem ile hesaplanmaktadır.

$S=\frac{2\left(\bar{R}_{2}-\bar{R}_{1}\right)}{n}$

\subsection{YŞST Eğrileri}

$\mathrm{Su}$ yapılarının planlaması, tasarımı, işletmesi ve yönetimine girdi sağlayan tüm mühendisliklerde yağış şiddeti (i), yağış süresi (t) ve tekerrür süresi (T) (YŞST) ilişkisi kullanılmaktadır. Bu ilişskilerin ortaya konulması 1930'lu yıllarda Sherman [35] ve Bernard (7) tarafından yapılan çalışmalar ve sonrasında ise 1960'lardan beri çoğu pek çok çalışmada coğrafi bölgelerin YŞST ilişkileri kullanılarak coğrafik dağılım çalışmaları yapılmıştır. Risk analizlerinde kullanmak üzere tekerrür ve yağgş süreleri için yağış şiddetlerini veya derinliklerini gösteren haritalar çizilmiştir [7,35].

i-t-T’nin genelleştirilmiş formu (16) numaralı denklemde verilmiştir.

$i=\frac{A(T)}{B(t)}$

$A(T)$ sadece tekerrür aralığına bağlı, $B(t)$ sadece yağış süresine bağlı fonksiyonlardır. $i$, Sherman [35] tarafindan 17 numaralı denklemle verilmiş, Bernard [7] tarafindan $\mathrm{c}=0$ alınması önerilmiştir.

$i=\frac{K \cdot T^{a}}{(t+c)^{b}}$

Her iki denklemde de $t$ yağış süresini, $T$ tekerrür süresini ve i yağış şiddetini göstermek üzere $a, b, c, K$ bölgesel ve coğrafi koşullara göre değişen parametrelerdir. (16) ve (17) numaralı denklemler yaygın olarak kullanılmaktadır. Bu denklemler üzerine yapılmış pek çok çalışma bulunmaktadır. 1994 yılında Koutsoyiannis [36] tarafından yapılan çalışmada (17) numaralı ilişkinin güvenli sonuçlar açısından uygun olmadığı, varyansın küçük tahmin edilmesine yol açtığı ifade edilmiştir. Koutsoyiannis [37] tarafından maksimum yağış şiddetleri Gumbel dağılımına uyduğu takdirde, (16) numaralı ilişkideki parametrelerin sabit değil, $T$ tekerrür aralığına bağlı olacağını vurgulamıştır.

Ülkemizde Çölaşan [38] tarafından YŞST eğrileri üzerine yapılan çalışma ilk çalışmalardan biri olarak kabul edilebilir. Bu çalışmada meteoroloji gözlem istasyonlarının YŞST eğrileri 
verilmiştir. Benzer şekilde DSİ tarafından 1970 yılında hazırlanan “Türkiye'de Maksimum Yağışların Frekans Atlası” çalışmasında 497 adet istasyona ait bilgi verilmiştir [39]. 1960'lı yıllardan itibaren günümüze kadar ülkemizde yapılmış pek çok çalışma bulunmaktadır.

Çalışmada standart süreli maksimum yağışların uygun oldukları dağılım fonksiyonları Kolmogrov-Smirnov uygunluk testi ile belirlenmiştir. Test kapsamında değerlendirilen standart dağılım fonksiyonları Normal (2 parametreli), Log-Normal (3 parametreli), Pearson (Tip-3), Kog-Pearson (Tip-3) ve Gumbel dağılım fonksiyonlarıdır. Ülkemizde maksimum yağış ve akım veri serilerinde yaygın olarak kullanılan dağılım fonksiyonlarıdır.

\section{UYGULAMA}

Öncelikle istasyonlara ait zaman serilerinde verilerin homojenliği Run Testi ile belirlenmiştir. İstasyonlara ait standart süreli yağış verilerinin aynı toplumdan geldiği ve birbirinden bağımsız olduğu varsayımları kontrol edilmiş ve detayları Çizelge-2'de sunulduğu üzere verilerin büyük çoğunluğunun $\% 95$ ve sadece 4 farklı istasyonda birer standart sürenin ise \%90 güven aralığında homojen oldukları sonucuna ulaşılmıştır.

\section{Çizelge 2 - Run (Swed-Eisenhart) Homojenlik Testi Sonuçları}

\begin{tabular}{|c|c|c|c|c|c|c|c|c|c|c|c|c|c|c|}
\hline \multirow[b]{2}{*}{ Seriler } & \multicolumn{2}{|c|}{ Florya } & \multicolumn{2}{|c|}{ Çorlu } & \multicolumn{2}{|c|}{ Göztepe } & \multicolumn{2}{|c|}{ Kartal } & \multicolumn{2}{|c|}{ Kumköy } & \multicolumn{2}{|c|}{ Sariyer } & \multicolumn{2}{|c|}{ Şile } \\
\hline & Homojen & H.Değil & Homojen & H.Değil & Homojen & H.Değil & Homojen & H.Değil & Homojen & H.Değil & Homojen & H.Değil & Homojen & H.Değil \\
\hline $5 \mathrm{dk}$ & $x$ & & $x$ & & $x$ & & $x$ & & $x$ & & $x$ & & $x$ & \\
\hline $10 \mathrm{dk}$ & $x$ & & $x$ & & $x$ & & $x$ & & $\mathrm{x}$ & & $\mathrm{x}$ & & $x$ & \\
\hline $15 \mathrm{dk}$ & $\mathrm{x}$ & & $\mathrm{x}$ & & $\mathrm{x}$ & & $\mathrm{x}$ & & $\mathrm{x}$ & & $\mathrm{x}$ & & $\mathrm{x}$ & \\
\hline $30 \mathrm{dk}$ & $\mathrm{x}$ & & $\mathrm{x}$ & & $x$ & & $\mathrm{x}$ & & $\mathrm{x}$ & & $x$ & & $x$ & \\
\hline $1 \mathrm{sa}$ & $\mathrm{x}$ & & $\mathrm{x}$ & & $\mathrm{x}$ & & $\mathrm{x}$ & & x (\%90) & & $\mathrm{x}$ & & $\mathrm{x}$ & \\
\hline $2 \mathrm{sa}$ & $\mathrm{x}$ & & $\mathrm{x}$ & & $\mathrm{x}$ & & $\mathrm{x}$ & & $\mathrm{x}$ & & $\mathrm{x}$ & & $\mathrm{x}$ & \\
\hline $3 \mathrm{sa}$ & $\mathrm{x}$ & & $\mathrm{x}$ & & $\mathrm{x}$ & & $\mathrm{x}$ & & $\mathrm{x}$ & & $\mathrm{x}$ & & $\mathrm{x}$ & \\
\hline 4 sa & $\mathrm{x}$ & & $\mathrm{x}$ & & $\mathrm{x}$ & & $\mathrm{x}$ & & $\mathrm{x}$ & & $\mathrm{x}$ & & $\mathrm{x}$ & \\
\hline $5 \mathrm{sa}$ & $x$ & & $\mathrm{x}$ & & $x$ & & $\mathrm{x}$ & & $x$ & & $x$ & & $x$ & \\
\hline $6 \mathrm{sa}$ & $\mathrm{x}$ & & $\mathrm{x}$ & & $\mathrm{x}$ & & $\mathrm{x}$ & & $\mathrm{x}$ & & $\mathrm{x}$ & & $\mathrm{x}$ & \\
\hline $8 \mathrm{sa}$ & $\mathrm{x}$ & & $\mathrm{x}$ & & $\mathrm{x}$ & & $\mathrm{x}$ & & $\mathrm{x}$ & & $\mathrm{x}$ & & $x$ & \\
\hline $12 \mathrm{sa}$ & $x$ & & $x$ & & $x$ & & $x$ & & $x$ & & $x$ & & $x$ & \\
\hline $18 \mathrm{sa}$ & $x(\% 90)$ & & $\mathrm{x}$ & & x (\%90) & & $x$ & & $\mathrm{x}$ & & $x$ & & $x$ & \\
\hline $24 \mathrm{sa}$ & $\mathrm{x}$ & & $\mathrm{x}$ & & $\mathrm{x}$ & & $\mathrm{x}$ & & $\mathrm{x}$ & & $\mathrm{x}$ & & x (\%90) & \\
\hline $\begin{array}{l}\text { Toplam } \\
\text { Adet }\end{array}$ & 14 & 0 & 14 & 0 & 14 & 0 & 14 & 0 & 14 & 0 & 14 & 0 & 14 & 0 \\
\hline
\end{tabular}

İkinci aşamada, tüm verilerde iç bağımlılığa bakılmış, Çizelge 3 'te otokorelasyon (iç bağımlılık) sayısının önemlilik testi sonuçları verilmiştir. Florya, Kartal ve Kumköy MGİ'lerin çeşitli süreli yağışlarında iç bağımlılık tespit edilmiş ve iç bağımlılık tespit edilen saatlere ön beyazlatma işlemi uygulanarak zaman serisi iç bağımlılıktan kurtarılmıştır. Çizelge 3 'te koyu renkle verilen saatler ön-beyazlatma işlemi uygulanan standart saatleri göstermektedir.

Üçüncü aşamada, tüm istasyonların verileri Mann-Kendall testine tabii tutulmuştur. İç bağımlılığı olan saatlerde ön beyazlatma işlemi uygulanmış veriler kullanılmıştır. MannKendall trend analizinde, yıllık atmosferik ve yağış konsantrasyonlarının zaman serilerinde eğilimin tespiti ve tahmini için geliştirilmiş MAKESENS programı [40] kullanılmıştır. MAKESENS iki tip istatistik analiz hesabı yapmaktadır. Birincisi, monotonik artı̧ veya azalış eğilimi parametrik olmayan Mann-Kendall analizi ile test edilir, ikincisi doğrusal 
eğilimin eğimi parametrik olmayan Sen metodu ile tahmin edilir. Burada, her iki yöntem de en temel formlarıyla kullanılmıştır. Mann-Kendall testinde, eğer veri sayısı 10 ve üzeri ise normal yaklaşım testi uygulanır. Bununla birlikte, eğer zaman serisinde veri sayısı 10'a yakın ve birkaç bağlı değer (örneğin eşit değerler gibi) varsa bu normal dağılımın geçerliliğini azaltabilir. Zaman serisinde istatistiksel olarak anlamlı bir eğilimin varlığ $Z$ değeriyle ölçülür. Pozitif (negatif) Z değeri artan (azalan) eğilimin göstergesidir. Çizelge 4 'te test Z değerleri ve anlamlılık düzeyleri verilmiştir. Sen'in parametrik olmayan yöntemi var olan bir eğilimin gerçek eğimini tahmin etmek için kullanılır. Sen Metodu eğilimin doğrusal olduğu varsayılan durumlarda kullanılmaktadır [41]. Çizelge 4'te Mann-Kendall testi ve Sen Eğilim Eğim metodu sonuçları verilmiştir.

Çizelge 3 - Otokorelasyon (İç Bağımlılık) Sayısının Önemlilik Testi Sonuçları

\begin{tabular}{|c|c|c|c|c|c|c|c|c|c|c|c|c|c|c|}
\hline \multirow[b]{2}{*}{ Seriler } & \multicolumn{2}{|c|}{ Florya } & \multicolumn{2}{|c|}{ Çorlu } & \multicolumn{2}{|c|}{ Göztepe } & \multicolumn{2}{|c|}{ Kartal } & \multicolumn{2}{|c|}{ Kumköy } & \multicolumn{2}{|c|}{ Sarıyer } & \multicolumn{2}{|c|}{ Şile } \\
\hline & Bağımlı & Bağımsız & Bağımlı & Bağımsız & Bağımlı & Bağımsız & Bağımlı & Bağımsız & Bağımlı & Bağımsız & Bağımlı & Bağımsız & Bağımlı & Bağımsız \\
\hline $5 \mathrm{dk}$ & & $x$ & & $x$ & & $x$ & & $x$ & & $x$ & & $x$ & & $x$ \\
\hline $10 \mathrm{dk}$ & & $x$ & & $x$ & & $x$ & & $\mathbf{x}$ & & $x$ & & $x$ & & $x$ \\
\hline $15 \mathrm{dk}$ & & $x$ & & $x$ & & $x$ & & $x$ & & $x$ & & $x$ & & $x$ \\
\hline $30 \mathrm{dk}$ & & $x$ & & $x$ & & $x$ & & $x$ & & X & & $x$ & & $x$ \\
\hline $1 \mathrm{sa}$ & & $x$ & & $x$ & & $x$ & & $x$ & & $\mathbf{x}$ & & $x$ & & $x$ \\
\hline $2 \mathrm{sa}$ & & $x$ & & $x$ & & $x$ & & $x$ & & $x$ & & $x$ & & $x$ \\
\hline $3 \mathrm{sa}$ & & $\mathbf{x}$ & & $x$ & & $x$ & & $x$ & & $x$ & & $x$ & & $x$ \\
\hline $4 \mathrm{sa}$ & & $\mathbf{X}$ & & $x$ & & $x$ & & $x$ & & $x$ & & $x$ & & $x$ \\
\hline $5 \mathrm{sa}$ & & $\mathbf{x}$ & & $x$ & & $x$ & & $x$ & & $x$ & & $x$ & & $x$ \\
\hline $6 \mathrm{sa}$ & & $\mathbf{x}$ & & $x$ & & $x$ & & $x$ & & $x$ & & $x$ & & $x$ \\
\hline $8 \mathrm{sa}$ & & $\mathbf{x}$ & & $x$ & & $x$ & & $x$ & & $x$ & & $x$ & & $x$ \\
\hline $12 \mathrm{sa}$ & & $x$ & & $x$ & & $x$ & & $x$ & & $x$ & & $x$ & & $x$ \\
\hline $18 \mathrm{sa}$ & & $x$ & & $x$ & & $x$ & & $x$ & & $x$ & & $x$ & & $x$ \\
\hline $24 \mathrm{sa}$ & & $x$ & & $x$ & & $x$ & & $x$ & & $\mathrm{x}$ & & $x$ & & $x$ \\
\hline $\begin{array}{l}\text { Toplam } \\
\text { Adet }\end{array}$ & 0 & 14 & 0 & 14 & 0 & 14 & 0 & 14 & 0 & 14 & 0 & 14 & 0 & 14 \\
\hline
\end{tabular}

X koyu renk olan saatler Prew hiten testine tabi tutulmuştur.

Çizelge 4 - Mann-Kendall Trend Analizi ve Sen Trend Ĕ̆im Metodu Sonuçları

\begin{tabular}{|c|c|c|c|c|c|c|c|c|c|c|c|c|c|c|c|c|c|c|c|c|c|}
\hline \multirow[b]{2}{*}{ Seriler } & \multicolumn{3}{|c|}{ Florya } & \multicolumn{3}{|c|}{ Çorlu } & \multicolumn{3}{|c|}{ Göztepe } & \multicolumn{3}{|c|}{ Kartal } & \multicolumn{3}{|c|}{ Kumköy } & \multicolumn{3}{|c|}{ Sarıyer } & \multicolumn{3}{|c|}{ Şile } \\
\hline & Test Z & Sig. & Q & Test Z & Sig. & $Q$ & Test Z & Sig. & Q & Test Z & Sig. & Q & Test Z & Sig. & $Q$ & Test Z & Sig. & $Q$ & Test Z & Sig. & $\mathrm{Q}$ \\
\hline $5 \mathrm{dk}$ & 0.99 & & 0.014 & 0.69 & & 0.016 & 0.8 & & 0.018 & -0.03 & & -0.002 & 1.22 & & 0.024 & 3.29 & ** & 0.070 & 1.41 & & 0.050 \\
\hline $10 \mathrm{dk}$ & 1.88 & + & 0.044 & 0.84 & & 0.034 & 1.28 & & 0.037 & -0.33 & & -0.023 & 1.77 & + & 0.062 & 2.96 & $* *$ & 0.091 & 0.88 & & 0.062 \\
\hline $15 \mathrm{dk}$ & 2.56 & * & 0.065 & 0.55 & & 0.027 & 1.42 & & 0.05 & -1.56 & & -0.122 & 2.10 & * & 0.09 & 2.89 & $* *$ & 0.109 & 1.28 & & 0.086 \\
\hline $30 \mathrm{dk}$ & 2.96 & $* *$ & 0.100 & 1.40 & & 0.100 & 2.10 & * & 0.091 & -1.20 & & -0.154 & 1.52 & & 0.124 & 2.78 & ** & 0.175 & 1.62 & & 0.140 \\
\hline $1 \mathrm{sa}$ & 3.24 & $* *$ & 0.132 & 2.02 & * & 0.158 & 2.30 & $*$ & 0.126 & -0.64 & & -0.113 & 1.29 & & 0.150 & 3.36 & $\star * * *$ & 0.248 & 1.54 & & 0.190 \\
\hline $2 \mathrm{sa}$ & 3.86 & $* * *$ & 0.163 & 2.35 & * & 0.229 & 2.33 & * & 0.141 & -0.33 & & -0.067 & 2.62 & ** & 0.388 & 3.60 & 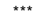 & 0.299 & 1.11 & & 0.188 \\
\hline $3 \mathrm{sa}$ & 2.85 & $\star * *$ & 0.162 & 2.26 & * & 0.212 & 2.91 & ** & 0.200 & -0.53 & & -0.116 & 2.82 & $* *$ & 0.455 & 4.03 & $* * *$ & 0.335 & 1.35 & & 0.216 \\
\hline $4 \mathrm{sa}$ & 3.05 & $* *$ & 0.190 & 2.27 & * & 0.210 & 2.72 & ** & 0.215 & -0.47 & & -0.133 & 3.07 & ** & 0.468 & 4.18 & $\star * \star *$ & 0.360 & 1.50 & & 0.262 \\
\hline $5 \mathrm{sa}$ & 2.98 & $* *$ & 0.191 & 2.38 & * & 0.211 & 2.92 & ** & 0.220 & -0.83 & & -0.170 & 3.11 & $* \star$ & 0.495 & 4.07 & $* \star *$ & 0.405 & 1.70 & + & 0.300 \\
\hline $6 \mathrm{sa}$ & 2.95 & $\star *$ & 0.184 & 2.05 & * & 0.181 & 3.08 & ** & 0.262 & -0.92 & & -0.250 & 2.92 & ** & 0.520 & 3.53 & $* * *$ & 0.400 & 1.97 & * & 0.399 \\
\hline $8 \mathrm{sa}$ & 2.73 & $* *$ & 0.185 & 1.83 & + & 0.179 & 3.06 & $* *$ & 0.264 & -0.85 & & -0.189 & 1.77 & + & 0.383 & 3.26 & $* *$ & 0.390 & 1.91 & + & 0.403 \\
\hline $12 \mathrm{sa}$ & 3.43 & $* * *$ & 0.226 & 2.38 & * & 0.224 & 2.59 & $* *$ & 0.236 & -0.77 & & -0.261 & 3.01 & $* *$ & 0.623 & 3.13 & $* *$ & 0.436 & 1.99 & * & 0.365 \\
\hline $18 \mathrm{sa}$ & 1.61 & & 0.118 & 1.98 & * & 0.234 & 1.01 & & 0.093 & -0.96 & & -0.297 & 2.52 & * & 0.530 & 3.25 & ** & 0.500 & 2.32 & * & 0.459 \\
\hline $24 \mathrm{sa}$ & -0.03 & & -0.005 & 1.59 & & 0.229 & -0.17 & & -0.011 & 0.00 & & 0.011 & 2.12 & * & 0.485 & 2.82 & $* *$ & 0.443 & 1.79 & + & 0.405 \\
\hline
\end{tabular}

Eğilim $\alpha=0.001$ anlamlılık düzeyinde ise $* * *$

Eğilim $\alpha=0.01$ anlamlılık düzeyinde ise $* *$

Eğilim $\alpha=0.05$ anlamlllık düzeyinde ise *

Eğilim $\alpha=0.1$ anlamlılık düzeyinde ise $\quad+$

Eğer hücre boş ise anlamlılık düzeyi $\alpha=0.1$ 'den büyüktür. 
Şekil-3'te sırasıyla Sarıyer MGİ'nin 24 sa ve 5 sa süreli yıllık en büyük yağış verisi eğilim grafikleri verilmiştir. Sarıyer MGİ'nin 24 saat süreli maksimum yağışlarında eğilim $\alpha=0.01$ anlamlılık düzeyindedir. Tüm istasyonların yağış verilerindeki artan (azalan) eğilimlerin anlamlılık düzeyleri Çizelge 4'te verilmiştir. Artan eğilimin daha net görülebilmesi anlamlılık düzeyinin $\alpha=0.001$ olduğu 5 sa süreli maksimum yağışlarına ait eğilim grafiği de Şekil-3'te verilmiştir.

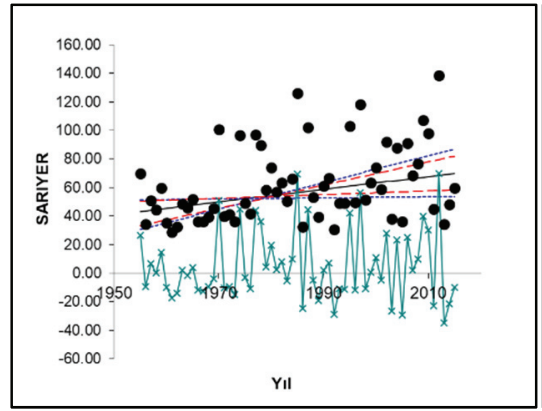

(a)

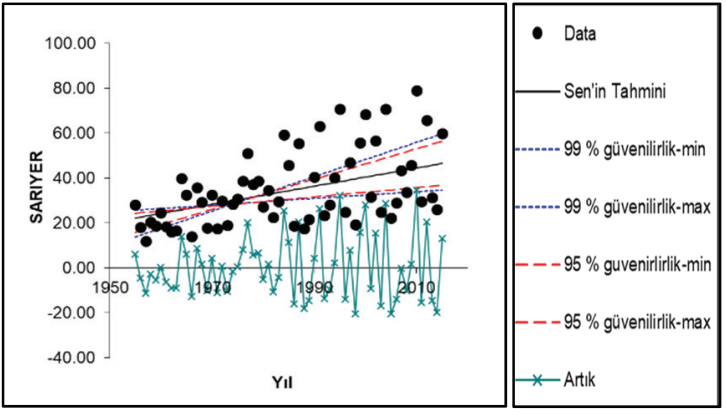

(b)

Şekil 3 - Sarıyer MGI’nin (a) 24 sa ve (b) 5 sa süreli yıllık en büyük yağış verisi trend grafiği

Mann-Kendall eğilim analizi ve Sen Eğim Metoduna ek olarak Yenilikçi Şen Yöntemi de yağış verilerine uygulanmış ve denklem (15)'te verilen eğim formülü ile hesaplanan eğim sonuçları Çizelge 5'te verilmiştir. Tüm istasyonlar için on dört adet standart zamanda gözlenen en büyük yağış verileri için Yenilikçi Şen Yöntemine göre trend grafikleri çizilmiş ancak burada sadece artan trende sahip Sarıyer MGI'nin (24 sa ve 5 sa'lik) ve azalan trende sahip Kartal MGİ'nin (1 sa ve 5 sa'lik) grafikleri örnek olarak verilmiştir (Şekil 4 ve 5).

Çizelge 5 - Yenilikçi Şen Yöntemi Sonuçları

\begin{tabular}{|c|c|c|c|c|c|c|c|c|c|c|c|c|c|c|c|c|c|c|c|c|c|}
\hline \multirow[b]{2}{*}{ Seriler } & \multirow[b]{2}{*}{ Yok } & \multicolumn{3}{|c|}{ Florya } & \multicolumn{2}{|c|}{ Çorlu } & \multicolumn{3}{|c|}{ Göztepe } & \multicolumn{3}{|c|}{ Kartal } & \multicolumn{3}{|c|}{ Kumköy } & \multicolumn{3}{|c|}{ Sarıyer } & \multicolumn{3}{|c|}{ Şile } \\
\hline & & Artış & Azalış & Yok & Artış & Azalış & Yok & Artış & Azalış & Yok & Artış & Azalış & Yok & Artış & Azalış & Yok & Artış & Azalış & Yok & Artış & Azalış \\
\hline $5 \mathrm{dk}$ & & & -0.002 & & & -0.016 & & 0.017 & & & & -0.034 & & & -0.005 & & 0.051 & & & 0.062 & \\
\hline $10 \mathrm{dk}$ & & 0.018 & & & & -0.019 & & 0.025 & & & & -0.040 & & 0.031 & & & 0.068 & & & 0.094 & \\
\hline $15 \mathrm{dk}$ & & 0.032 & & & & -0.034 & & 0.020 & & & & -0.001 & & 0.072 & & & 0.082 & & & 0.134 & \\
\hline $30 \mathrm{dk}$ & & 0.067 & & & 0.032 & & & 0.067 & & & & -0.029 & & 0.218 & & & 0.142 & & & 0.302 & \\
\hline $1 \mathrm{sa}$ & & 0.100 & & & 0.098 & & & 0.077 & & & & -0.037 & & 0.392 & & & 0.257 & & & 0.459 & \\
\hline $2 \mathrm{sa}$ & & 0.125 & & & 0.119 & & & 0.103 & & & & -0.053 & & 0.419 & & & 0.320 & & & 0.398 & \\
\hline $3 \mathrm{sa}$ & & 0.180 & & & 0.124 & & & 0.148 & & & & -0.106 & & 0.514 & & & 0.353 & & & 0.436 & \\
\hline $4 \mathrm{sa}$ & & 0.216 & & & 0.112 & & & 0.162 & & & & -0.100 & & 0.600 & & & 0.383 & & & 0.487 & \\
\hline $5 \mathrm{sa}$ & & 0.237 & & & 0.134 & & & 0.186 & & & & -0.135 & & 0.660 & & & 0.431 & & & 0.513 & \\
\hline $6 \mathrm{sa}$ & & 0.222 & & & 0.129 & & & 0.231 & & & & -0.117 & & 0.694 & & & 0.419 & & & 0.649 & \\
\hline $8 \mathrm{sa}$ & & 0.152 & & & 0.131 & & & 0.225 & & & & -0.106 & & 0.747 & & & 0.376 & & & 0.671 & \\
\hline $12 \mathrm{sa}$ & & 0.186 & & & 0.217 & & & 0.212 & & & & -0.109 & & 0.910 & & & 0.344 & & & 0.665 & \\
\hline $18 \mathrm{sa}$ & & 0.133 & & & 0.263 & & & 0.104 & & & & -0.019 & & 0.865 & & & 0.425 & & & 0.657 & \\
\hline $24 \mathrm{sa}$ & & 0.021 & & & 0.231 & & & 0.030 & & & 0.085 & & & 0.750 & & & 0.384 & & & 0.329 & \\
\hline $\begin{array}{l}\text { Toplam } \\
\text { Adet }\end{array}$ & 0 & 13 & 1 & 0 & 11 & 3 & 0 & 14 & 0 & 0 & 1 & 13 & 0 & 13 & 1 & 0 & 14 & 0 & 0 & 14 & 0 \\
\hline
\end{tabular}




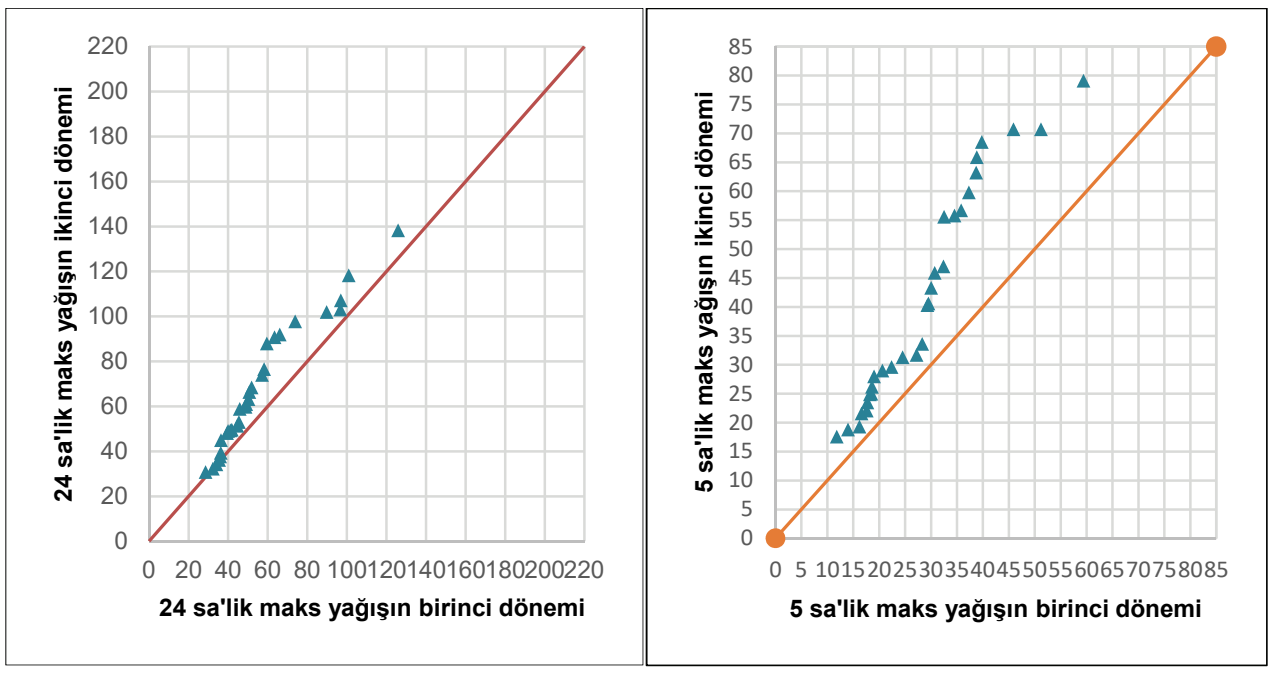

(a)

(b)

Şekil 4 - Sarıyer MGÍnin (a) 24 sa ve (b) 5 sa süreli yıllık en büyük yağış verisinin Yenilikçi Şen Yöntemine göre trend grafiği

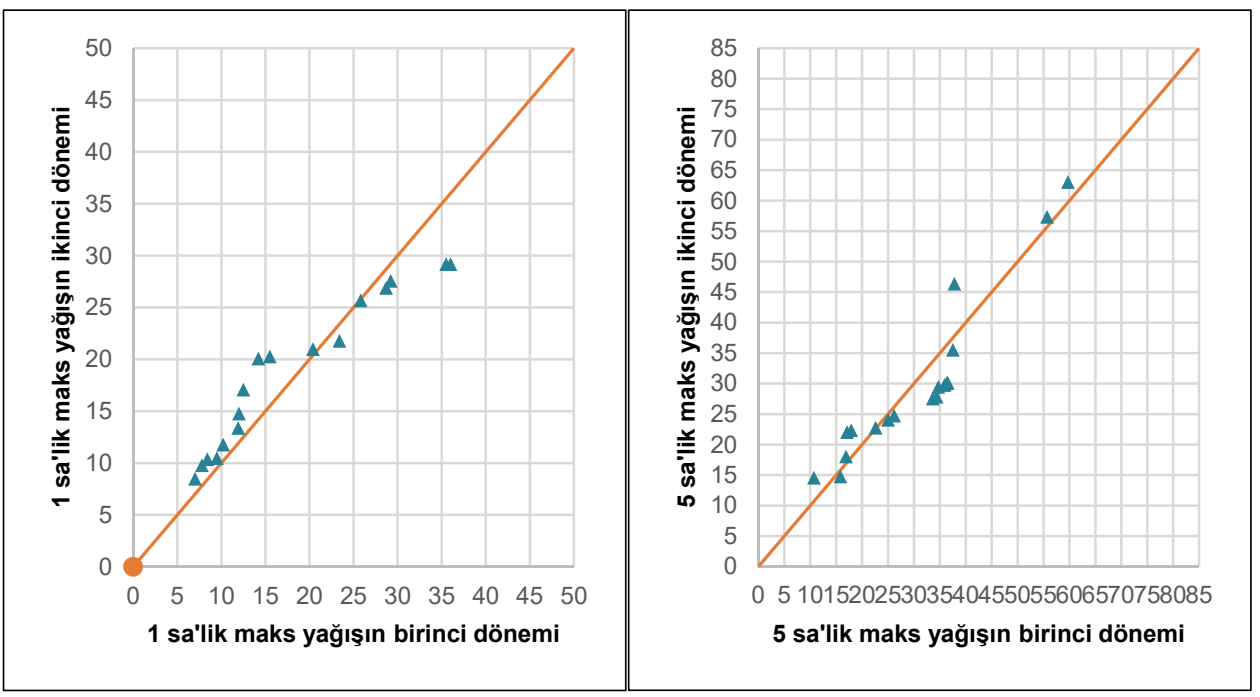

(a)

(b)

Şekil 5 - Kartal MGÍnin (a) 1 sa ve (b) 5 sa süreli yıllık en büyük yağış verisinin Yenilikçi Şen Yöntemine göre trend grafiği

Bilindiği üzere birim zamanda düşen yağış yüksekliği yağış şiddetini vermektedir. Yağış şiddeti, yüzeysel akış ve toprak erozyonu nedeniyle gerek insan hayatı ve sosyal işleyiş 
açısından, gerekse boyutlandırmada önem arz etmektedir. Örneğin, yağmur suyu kanallarının boyutlandırılmasına esas olacak yağış şiddetinin seçiminde tekerrür süresi büyüdükçe proje maliyeti artacağından, önlenecek zarar ile yapılacak yatırımın maliyetini kapsayan faydamaliyet analizinin yapılması ve en uygun yatırımı bulabilmek adına YŞST eğrilerinin zaman içerisinde değişiminin belirlenmesi karar vericiler açısından değerli bir bilgidir. Bu nedenle, çalışmada son olarak, su kaynakları sistemlerinin tasarımında önemli bilgi sağlayan YŞST eğrileri tüm istasyonlar için 2, 5, 10, 25, 50 ve 100 yıl dönüş aralıklarında çizilmiştir. YŞST eğrilerinin çizilmesinde gözlem istasyonuna ait 24 saatlik yıllık en büyük yağış yüksekliği (mm) değerlerinin dağılımları kullanılmıştır. İlk olarak tüm veri aralığı için YŞST eğrileri çizilmiş, daha sonra zaman serisi iki eşit aralığa bölünerek birinci yarı ve ikinci yarı olmak üzere YŞST eğrileri çizilmiştir.

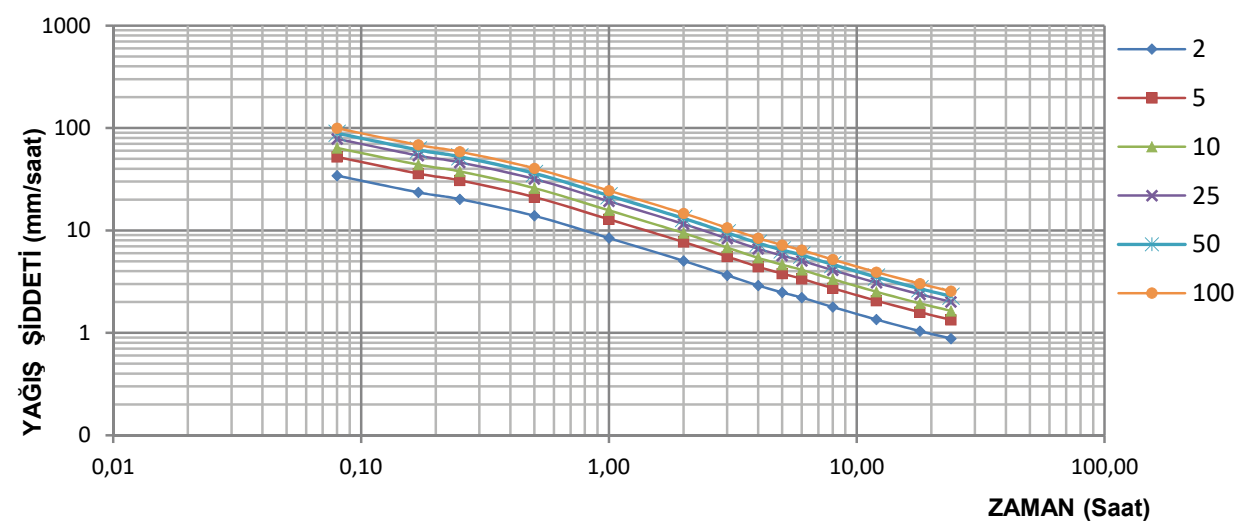

Şekil 6 - Yă̆ış Şiddeti - Süre - Frekans Ĕ̈rileri Sarıyer MGİ (1955-2015)

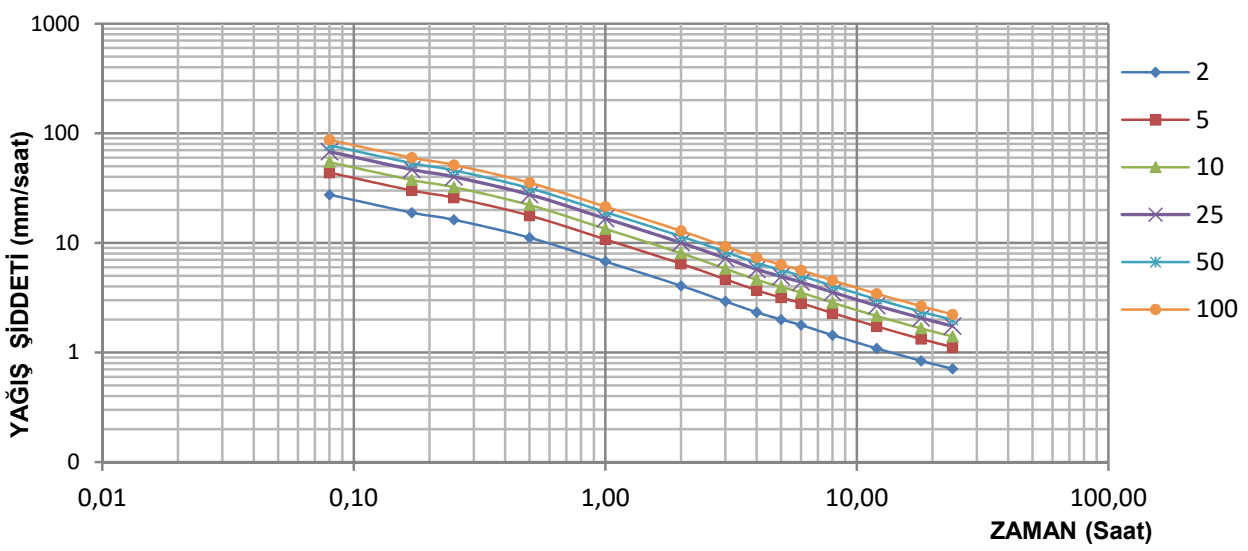

Şekil 7 - Yă̆ış Şiddeti - Süre - Frekans Eğrileri Sarıyer MGİ (1955-1985) 


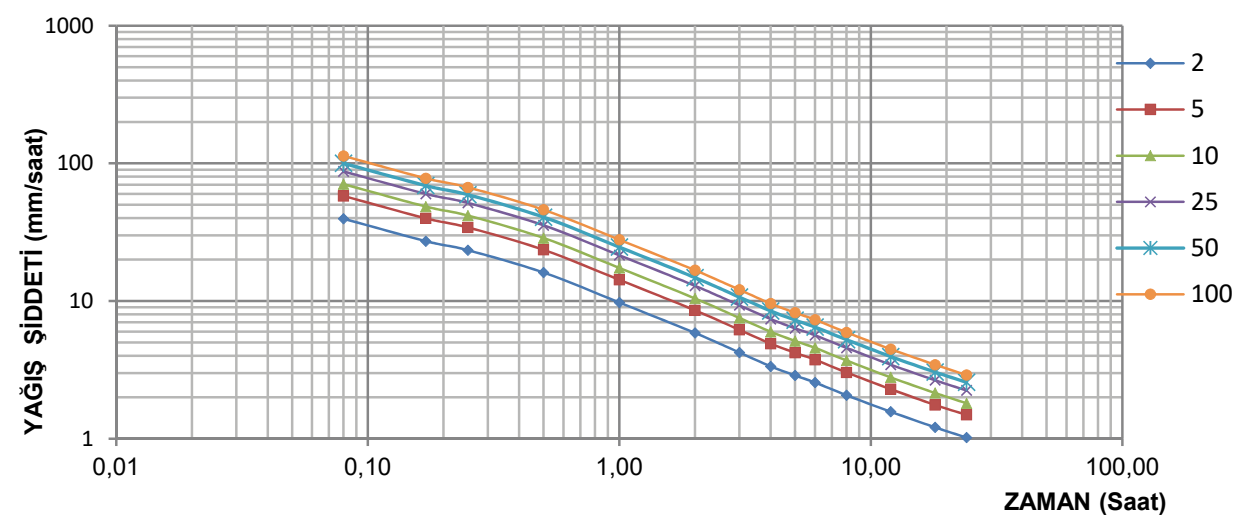

Şekil 8 - Yağış Şiddeti - Süre - Frekans Ĕ̆rileri Sartyer MGİ (1986-2015)

Çizelge 6 - Ístasyonlara ait Yağış Şiddeti Verilerine ait Bă̆ll Hata (\%)

(a) Zaman serilerinin 2. yarısının 1. yarıya göre değişimi

\begin{tabular}{|l|l|l|l|l|l|l|l|}
\hline $\begin{array}{l}\text { Tekerrür } \\
\text { Yll }\end{array}$ & FLORYA & ÇORLU & GÖZTEPE & KARTAL & KUMKÖY & SARIYER & ŞILE \\
\hline 2 & 3.73 & 9.7 & 1.41 & 4.37 & 15.63 & 30.58 & 15.5 \\
\hline 5 & 9.32 & 15.56 & 4.19 & 5.53 & 31.64 & 24.59 & 14.03 \\
\hline 10 & 14.81 & 18.28 & 5.34 & 6.08 & 39.97 & 22.87 & 10.55 \\
\hline 25 & 22.3 & 20.94 & 6.27 & 6.8 & 48.51 & 22.28 & 4.47 \\
\hline 50 & 27.92 & 22.55 & 6.81 & 7.54 & 53.8 & 22.52 & $\mathbf{1 . 0 9}$ \\
\hline 100 & 33.28 & 23.86 & 7.23 & 8.39 & 58.32 & 23.11 & $\mathbf{6 . 9}$ \\
\hline
\end{tabular}

(b) Zaman serilerinin 2. yarısının tüm periyoda göre değişimi

\begin{tabular}{|l|l|l|l|l|l|l|l|}
\hline $\begin{array}{l}\text { Tekerrür } \\
\text { Yılı }\end{array}$ & FLORYA & ÇORLU & GÖZTEPE & KARTAL & KUMKÖY & SARIYER & ŞILE \\
\hline 2 & 2.64 & 5.05 & 1.07 & 3.29 & 11.58 & 13.72 & 7.9 \\
\hline 5 & 5.15 & 5.51 & 5.04 & 1.59 & 18.04 & 9.98 & 7.07 \\
\hline 10 & 6.95 & 7.21 & 6.83 & 2.14 & 20.52 & 9.73 & 5.47 \\
\hline 25 & 9.25 & 10.66 & 8.56 & 4.7 & 22.37 & 10.42 & 2.81 \\
\hline 50 & 10.95 & 13.85 & 9.57 & 7.54 & 23.21 & 11.27 & 0.48 \\
\hline 100 & 12.6 & 17.36 & 10.4 & 10.86 & 23.71 & 12.26 & $\mathbf{2 . 0 0}$ \\
\hline
\end{tabular}


Çalışmada tüm istasyonlar için YŞST eğrileri çizilmiş ancak sadece Sarıyer MGİ'nin 24 saatlik YŞST eğrileri Şekil 6, Şekil 7 ve Şekil 8'de verilmiştir. 1986-2015'i kapsayan ikinci yarıda yağış şiddetinin tüm gözlem süresi ve 1955-1985 periyoduna göre arttığ1 görülmektedir. 1. yarı ve 2. yarı için hesaplanan yağış şiddetlerinin ( $\mathrm{mm} / \mathrm{sa})$ hem tüm gözlem süresi hem de birbirleriyle karşılaştırılabilmesi için bağıl hatalar hesaplanarak tespit edilmiştir. Çizelge 6-(a)'da zaman serilerinin 2. yarısının 1. yarısına göre değişimi, 6-(b)'de 2. yarının tüm periyoda göre değişimini gösteren bağıl hatalar verilmiştir.

Bir havzada akım verilerinin mevcut olmaması durumunda sentetik birim hidrograflardan faydalanılmaktadır. Bu çalışmada, yağış verilerindeki trendin taşkın debilerine olan etkisinin bir ifadesi olarak Sarıyer MGI'nin temsil ettiği Bekâr Deresinin çeşitli tekerrürlerde taşkın debileri Mockus Sentetik Birim Hidrograf yöntemiyle tüm gözlem süresi 1. yarı ve 2. yarı için hesaplanmıştır. Şehirleşmenin etkisi dikkate alınmadan, sadece iklim değişikliği ve değişiminden kaynaklanan farkı ortaya koyabilmek adına havza karakteristikleri ve CNII eğri numarası sabit tutulmuş yağıştaki artış/azalış dikkate alınarak taşkın debisindeki değişim hesaplanmıştır. Sentetik birim hidrograf yöntemlerinden olan Mockus Sentetik Yöntemi, toplanma süresi $\left(\mathrm{t}_{\mathrm{c}}\right) 30$ saatten az olan drenaj alanları için uygundur. Toplanma süresi daha büyük olan havzalar daha küçük alanlara ayrılarak her bir alan için hidrograflar hesaplanır gecikme sürelerine göre süperpoze edilir. Sağanak süresinin uygun seçilmesi önemlidir [42].

\section{SONUÇLAR}

İstanbul ilinde mevcut yağış rejimi ve topoğrafyası nedeniyle çok sayıda taşkın olayı meydana gelmektedir. Son yıllarda taşkın olaylarının sayısında ve verdiği zararda gözlenen artış, iklim değişkenliği ve değişimi ile açıklanmaya çalışılmaktadır. Gerek sosyal, gerek çevresel/tarımsal pek çok sektörün iklim değişiminden etkilendiği bilinmektedir. Eylül 2009'da İstanbul genelinde yaşanan sel felaketinden bugüne 10 yıl geçmiş bulunmaktadır. Geçtiğimiz süreçte yağışlardaki artan/azalan değişimin ortaya konulması gerekliliğinden yola çıkarak bu çalışmada üç farklı yöntemle değerlendirmeler yapılmıştır. Elde edilen sonuçlar aşağıda verilmiştir.

İstanbul şehri drenaj altyapısı, köprüler, menfezler ve su yapılarının planlanmasında maksimum yağışların frekans analizi en temel bilgidir. Son yıllarda İstanbul şehrinde pek çok şehir seli meydana gelmiştir. Bu sellerin zararlarından korunmak, şehrin altyapısının gerçekleşen şiddetli yağışlardan kaynaklanan akış hacmini, uygun tasarlanmış şehir yağmur drenaj hatları yardımıyla uzaklaştırmakla mümkündür. Bu çalışma kapsamında iklim değişkenliği ve değişiminin İstanbul şehri ve civarında bulunan Meteoroloji Gözlem İstasyonlarının YŞST eğrilerinde meydana getirdiği etki incelenmiştir. Şehir sellerinde ve taşkınlarda şehirleşmenin yağış-akış ilişkilerinde meydana getirdiği etki de çok önemli olmakla birlikte, bu çalışmanın kapsamı haricindedir.

1. Çalışmada, Florya, Sarıyer, Kumköy, Çorlu, Şile, Göztepe, Kartal olmak üzere plüviyograflı yedi adet meteoroloji gözlem istasyonuna (MGI) ait çeşitli süreli (5 dk, 10 dk, $15 \mathrm{dk}, 30 \mathrm{dk}, 1 \mathrm{sa}, 2 \mathrm{sa}, 3 \mathrm{sa}, 4 \mathrm{sa}, 5 \mathrm{sa}, 6 \mathrm{sa}, 8 \mathrm{sa}, 12 \mathrm{sa}, 18 \mathrm{sa}, 24 \mathrm{sa})$ yıllık en büyük yağış yüksekliği $(\mathrm{mm})$ değerlerinin tamamına Mann-Kendall eğilim analizi ve Sen Eğilim Eğim Metodu uygulanmıştır. Çizelge 4'ten görüleceğgi üzere Sarıyer, Şile, Kumköy, Çorlu istasyonlarına ait yıllık en büyük yağış yüksekliklerinin tamamında anlamlı bir artış tespit edilirken, Florya ve Göztepe istasyonlarına ait 24 saat süreli 
zaman serilerinde azalış tespit edilmiştir. Kartal istasyonunda 24 saat süreli yağışlarda artış görülürken diğer tüm standart zamanlara ait zaman serilerinde azalış görülmüştür. Sonuç olarak, İstanbul ili ve civarındaki bu yedi adet istasyondan Kartal MGİ haricindeki tüm istasyonlarda, $5 \mathrm{dk}, 10 \mathrm{dk}, 15 \mathrm{dk}, 30 \mathrm{dk}, 1 \mathrm{sa}, 2 \mathrm{sa}, 3 \mathrm{sa}, 4 \mathrm{sa}, 5 \mathrm{sa}, 6 \mathrm{sa}, 8 \mathrm{sa}, 12 \mathrm{sa}$, 18 sa'lik yıllık en büyük yağış yüksekliği $(\mathrm{mm})$ değerlerinde artış tespit edilmiştir. Şekil3 ve Şekil-4'te sırasıyla artan ve azalan eğilimin görülebilmesi için grafikler verilmiştir. Şekil-3'te monotonik trend, Şekil-4'te ise monotonik olmayan bir trend net olarak görülmektedir.

2. Yenilikçi Şen Metoduna göre istasyonların çeşitli süreli ( $5 \mathrm{dk}, 10 \mathrm{dk}, 15 \mathrm{dk}, 30 \mathrm{dk}, 1 \mathrm{sa}$, $2 \mathrm{sa}, 3 \mathrm{sa}, 4 \mathrm{sa}, 5 \mathrm{sa}, 6 \mathrm{sa}, 8 \mathrm{sa}, 12 \mathrm{sa}, 18 \mathrm{sa}, 24 \mathrm{sa})$ yıllık en büyük yağış yüksekliği (mm) değerlerinin Şen eğimi hesaplanmış ve Çizelge 4'te verilmiştir. İstasyonların zaman serilerinin büyük çoğunluğunda artış tespit edilmiştir. Ufak farklar dışında sonuçları Mann-Kendall eğilim analizi ve Sen Eğilim Eğim Metodu sonuçları ile oldukça uyumludur. İstasyonlara ait tüm standart zamanların yağış verileri için Şen trend grafikleri ayrı ayrı çizilmiştir. Çizelge 5 'te verilen Şen Eğimlerinden trendin güçlü mü belli belirsiz mi olduğu görülmektedir. Ancak özetle yapılan incelemede;

a. Mann-Kendall testinin tersine Florya MGI'nin 5 dk'lık en büyük yağış yüksekliğinde, Çorlu MGİ'nin 5dk, $10 \mathrm{dk}$ ve $15 \mathrm{dk}$ 'lık yağış yüksekliklerinde ve Kumköy MGİ'nin 5 dk'lık en büyük yağış yüksekliğinde azalış, Florya ve Göztepe MGİ'nin 24 sa'lik en büyük yağış yüksekliğinde artış tespit edilmiştir.

b. Sarıyer MGI'nin tüm zaman serilerinde monotonik artan trend görülmüş olup orta büyüklükte ve yüksek yağışlarda artış daha fazladır.

c. Florya MGİ'nin tüm zaman serilerinde belli belirsiz monotonik olmayan artış/azalış tespit edilmiş olup büyük çoğunluğunda yağış verileri 1:1 çizgisine çok yakın konumlanmıştır.

d. Çorlu MGI'nin tüm zaman serilerinde monotonik olmayan artış/azalış tespit edilmiş olup benzer şekilde büyük çoğunluğunda yağış verileri 1:1 çizgisine çok yakın konumlanmıştır.

e. Göztepe MGİ'de monotonik olmayan artış görülmüş olup tüm zaman serilerinde küçük ve orta büyüklükteki verilerde artış tespit edilmiştir.

f. Kartal MGİ'nin 24 sa'lik zaman serisi hariç tamamında hafif bir azalış görülmüştür.

g. Şile MGİ'de ise tüm zaman serilerinde monotonik artış tespit edilmiştir.

3. Çizelge 6'da verilen bağıl hatalara bakıldığında istasyonların tamamında tüm gözlem süresi ve gözlem süresinin ilk yarısına göre ikinci yarısında yağış şiddetinin ne yönde değiştiği görülmektedir. Tüm istasyonların gözlem süresinin 2.yarısına ait yağış şiddetinde 1. yarıya kıyasla artış görülmüş olup sadece Şile MGİ'nin 50 ve 100 yıl tekerrürlü yağış şiddetinde 2. yarıda azalış tespit edilmiştir. Benzer şekilde, tüm istasyonlarda zaman serisinin 2. yarısına ait yağış şiddetinde tüm gözlem süresine kıyasla artış görülmüş olup sadece Şile MGİ'nin 100 yıl tekerrürlü yağış şiddetinde 2. yarıda azalış tespit edilmiştir.

İkinci yarının 2 yıl tekerrürlü yağış şiddetlerine bakıldığında Sarıyer MGİ'nin yağış şiddetindeki birinci yarıya göre artışı \%30'u geçtiği görülmektedir. 100 yıl tekerrürlü 
yağış şiddetlerine bakıldığında Kumköy, Florya, Çorlu ve Sarıyer MGİnin artışları \%20'lerin üzerindedir. Yağış şiddetindeki bu artışların su yapıları tasarımlarında dikkate alınması gereklidir. Örneğin Sarıyer MGİ'nin Çizelge 6 (b)'de tekerrürlü yağış şiddetlerinde tüm periyoda göre ikinci yarıda ortalama \%11.23'lük bir artış meydana gelmiştir.

4. Sarıyer MGİ'nin temsil ettiği $7.0 \mathrm{~km}^{2}$ yağış alanına sahip Bekâr Deresinin çeşitli tekerrürlerde taşkın debileri Mockus Sentetik Birim Hidrograf yöntemi kullanılarak tüm periyod, 1. yarı ve 2. yarı için hesaplanmıştır.. Bekâr Deresi üzerinde gözlem süresinin son yarısında 500 yıl tekerrürlü taşkın debisi tüm periyoda göre $\% 35$ oranında, ilk yarısına göre ise \%60 oranında artmıştır. Bu durum su yapıları tasarımında yağış verisindeki trendlerin de dikkate alınmasının önemini ortaya koymaktadır.

Sonuç olarak, İstanbul ilini temsil eden Florya, Sarıyer, Kumköy, Çorlu, Şile, Göztepe, MGI'lerin $5 \mathrm{dk}, 10 \mathrm{dk}, 15 \mathrm{dk}, 30 \mathrm{dk}, 1 \mathrm{sa}, 2 \mathrm{sa}, 3 \mathrm{sa}, 4 \mathrm{sa}, 5 \mathrm{sa}, 6 \mathrm{sa}, 8 \mathrm{sa}, 12 \mathrm{sa}, 18 \mathrm{sa}$ 'lik yıllık en büyük yağış yüksekliği $(\mathrm{mm})$ değerlerinde artış tespit edilmiştir. İklim değişikliğinin de etkileri düşünüldüğünde geleceğe yönelik su temini, sslah, rekreasyon vb yapıların tasarımında taşkın tekerrürlerinin Çizelge 5'te verilen oranlarda artırılarak değerlendirilmesi ve diğer bölgeler için ise iki eşit dönem ve tüm periyot analizlerinin yapılması pratik bir yaklaşım olarak önerilmektedir.

Ayrıca, iklim ve hidroloji çalışmalarında araştırmacıların en çok karşılaştığı zorluk veri eksikliğidir. Türkiye'de bölgesel bazda veri ihtiyaçlarını ve mevcudiyetini tartışmak üzere çoklu kurum işbirliğinin oluşturulması ve etkin bir şekilde yürütülmesinin faydalı olacağı düşünülmektedir.

\section{Kaynaklar}

[1] Trenberth, K. E., (2011) Changes in precipitation with climate change. Clim Res 47, 123.

[2] Intergovernmental Panel on Climate Change (IPCC). (2007). "Climate change 2007: Physical science basis." Contribution of Working Group I to the 4th Assessment Rep. of the Intergovernmental Panel on Climate Change, S. Solomon, et al., eds., Cambridge University Press, New York.

[3] Intergovernmental Panel on Climate Change (IPCC). (2008). "Climate change and water." Technical Paper of the Intergovernmental Panel on Climate Change, B. C. Bates, et al., eds., IPCC Secretariat, Geneva, Switzerland.

[4] Kundzewicz, Z. W., et al. (2005). "Summer floods in Central Europe - Climate change track" Nat. Hazards, 36(1-2), 165-189.

[5] Collins, M. J. (2009). "Evidence for changing flood risk in New England since the late 20th century." J. Am. Water Resour. Assoc., 45(2), 279-290.

[6] Cheng, L. \& AghaKouchak, A., (2014). Nonstationary Precipitation IntensityDuration-Frequency Curves for Infrastructure Design in a Changing Climate. Nature: Scientific Reports, Volume 4, p. 7093. 
[7] Bernard, M. M., (1932). Formulas for Rainfall Intensities of Long Duration, 96: 592624.

[8] Hershfield, D.M., (1961) Rainfall frequency atlas of the United States for durations from 30 minutes to 24 hours and return periods from 1 to 100 Years, US Weather Bureau Technical Paper 40, Washington DC.

[9] Chow, V.T., (1964) Statistical and probability analysis of hydrologic data. Part I: frequency analysis, Handbook of Applied Hydrology. Sec. 8-I, 8.1-8.42, Mc Graw Hill, New York.

[10] Miller J.F., Frederick R.H., Tracey R.J. \& Nerc. (1973) Precipitation frequency analysis of the Western US, NOAA Atlas, National Weather Service, US Department of Commerce, Siver Spring, MD.

[11] Koutsoyiannis D., Kozonis D. \& Manetas A. A (1998) Mathematical framework for studying rainfal IDF relationships. J Hydrol, 206, 118-135.

[12] Linsley R.K. Jr., Kohler M.A. \& Paulus J.L.H. (1975) Hydrology for Engineers, 2nd ed. Tokyo: Mc Graw Hill.

[13] Chen C.I., (1983) Rainfall intensity-duration-frequency formulas. J Hydrol Eng, 109, (12), 1603-1621.

[14] Burn, D. H., Mansour, R., Zhang, K., and Whitfield, P. H. (2011). "Trends and variability in extreme rainfall events in British Columbia." Can. Water Resour. J., $36(1), 67-82$.

[15] Fujibe, F., Yamazaki, N., Katsuyama, M., and Kobayashi, K. (2005). “The increasing trend of intense precipitation in Japan based on four-hourly data for a hundred years." SOLA, 1(2005), 41-44.

[16] Douglas, E. M., and Fairbank, C. A. (2011). "Is precipitation in northern New England becoming more extreme? Statistical analysis of extreme rainfall in Massachusetts, New Hampshire, and Maine and updated estimates of the 100-year storm.” J. Hydrol. Eng., 10.1061/(ASCE)HE .1943-5584.0000303, 203-217.

[17] Villarini, G., Smith, J. A., Baeck, M. L., and Krajewski, W. F. (2011). "Examining flood frequency distributions in the midwest U.S.” J. Am. Water Resour. Assoc., 47(3), 447-463.

[18] Manton, M. J., Della-Marta, P. M., Haylock, M. R., Hennessy, K. J., Nicholls, N., 741 Chambers, L. E., Yee, D. (2001). Trends in extreme daily rainfall and temperature in Southeast Asia and the South Pacific: 1961-1998. International Journal of Climatology, 21(3), 269-284. doi:10.1002/joc.610

[19] Westra, S., Alexander, L. V., \& Zwiers, F. W. (2013). Global Increasing Trends in Annual 835 Maximum Daily Precipitation. Journal of Climate, 26(11), 3904-3918. 836 doi:10.1175/jcli-d-12-00502.1

[20] Haktanır, T., Citakoglu, H., (2014) Trend, Independence, Stationarity, and Homogeneity Tests on Maximum Rainfall Series of Standard Durations Recorded in TurkeyJournal of Hydrologic Engineering, ASCE, ISSN 1084-0699/05014009(13). 
[21] Karahan, H., Ayvaz, M. T., Gürarslan, G., (2008) Şiddet-Süre-Frekans Bağıntısının Genetik Algoritma ile Belirlenmesi: GAP Örneği. İMO Teknik Dergi, 2008 4393-4407, Yaz1 290.

[22] Almazroui, M., Şen, Z., Mohorji, A.M., Islam, M.N., (2018) Impacts of Climate Change on Water Engineering Structures in Arid Regions: Case Studies in Turkey and Saudi Arabia, Earth Systems and Environment https://doi.org/10.1007/s41748-018$\underline{0082-6}$

[23] Korkmaz, B., Şen, K., Aksu, H., (2019) Orta Karadeniz İçin Dönemsel Yağış-Şiddet ve Süre Analizi,10. Ulusal Hidroloji Kongresi, Muğla.

[24] Y.S. Güçlü, E. Sisman and M.Ö. Yelegen (2016) Climate change and frequencyintensity-duration (FID) curves for Florya station, Istanbul, J Flood Risk Management.

[25] Karakuş, C.B., (2017) Trend Analysis Methods for Hydro-Meteorological Parameters, International Journal of Scientific and Technological Research, Vol 3, No.2, 22-32.

[26] Oliver, R.L.(1981) Measurement and Evaluation of Satisfaction Processes in Retail Settings. Journal Retailing, 57 (3), 25-48.

[27] Salas, J. D., J. R. Delleur, Yevjevich, and W. L. Lane, (1980) Applied Modeling of Hydrologic Time Series, Water Resources Publications, Littleton, CO.

[28] Von Storch H, Navarra A. (1999). Analysis of Climate Variability: Applications of Statistical Rechniques. Springer Verlag: Berlin.

[29] Kendall, M.G., (1975). Rank Correlation Methods. Charles Griffin. London.

[30] Mann, H. B., (1945). Non-parametric Test Against Trend. Econometrika, Vol. 13, pp. 245-259.

[31] Yu, Y.S., Zou, S., Whittemore, D., 1993, Non-Parametric Trend Analysis of Water Quality Data of Rivers in Kansas, Journal of Hydrology 150: 61-80.

[32] Şen, Z., (2012) "Innovative Trend Analysis Methodology”, Journal of Hydrologic Engineerıng (C) Asce, Vol. 17, pp. 1042-1046.

[33] Şen, Z., (2013) “Trend Identification Simulation and Application", Journal of Hydrological Engineering, Vol. 19.

[34] Çeribaşı, G., (2018)“Batı Karadeniz Havzasının Yağış Verilerinin Yenilikçi Şen Yöntemi İle Analizi”, Academic Platform Journal of Engineering and Science 6-3, 168173.

[35] Sherman, C. W., (1931). Frequency and Intensity of Excessive Rainfall At Boston, Massachusetts, Transaction Paper, 95: 951-960.

[36] Koutsoyiannis, D., (1994). A Stochastic Disaggregation Method for Design Storm and Flood Synthesis, Journal of Hydrology, 156: 193-225

[37] Koutsoyiannis, D., (1996). Statistical Hydrology, National Technical University Press, Athens. 
[38] Çölaşan Ü.E, (1969) Türkiye'nin Yağış Şiddet Süre Tekerrür Haritaları, Tarım Bakanlığı Meteoroloji İşleri Gn. Md., Ankara, 84 sayfa

[39] DSİ, 1990. Türkiye’ de Maksimum Yağış̧ların Frekans Atlası, L. I., Noktasal Yağışların Frekans Analizi, DSİ Genel Müdürlüğü, Ankara.

[40] Finlandiya Meteoroloji Ofisi (Finnish Meteorological Institute), (2002) Detecting Trends of Annual Values of Atmospheric Pollutants by the Mann-Kendall Test and Sen's Slope Estimates -The Excel Template Application (MAKESENS).

[41] Salmi, T., Määttä, A., Anttila, P., Ruoho-Airola, T., Amnell, T., (2002) Detecting Trends Of Annual Values Of Atmospheric Pollutants By The Mann-Kendall Test And Sen's Slope Estimates-The Excel Template Application Makesens, Finnish Meteorological Institute, Publications on air quality, No:31, Helsinki.

[42] Özdemir, H., (1972) Uygulamalı Taşkın Hidrolojisi, DSİ Matbaası, 221, Ankara. 